\title{
Risco e (in)segurança na missão policial
}

\author{
Risk and (in)security in the police mission
}

Maria Cecília de Souza Minayo ${ }^{1}$

Sérgio Adorno ${ }^{2}$

\footnotetext{
${ }^{1}$ Claves, Escola Nacional de Saúde Pública, Fundação Oswaldo Cruz. Av. Brasil 4036/700, Manguinhos. 21040-361 Rio de Janeiro RJ.maminayo@terra.com.br ${ }^{2}$ Departamento de Sociologia, Faculdade de Filosofia Letras e Ciências Humanas, Universidade de São Paulo.
}

Abstract This paper introduces a discussion on the history and use of the concepts of risk and security applied to the police officer's mission. The text is developed in an essay format that shows how both terms developed under the constitution of modern industrial societies. The authors begin with the assumption that the organizational structure of the police in various parts of the world retains the same logic since they were created during the eighteenth and nineteenth centuries and that this format is in crisis: whether it is because the concept of risk and current management thereof has now become much broader; or because the concept of security has also deepened and broadened, fleeing from the scope of the police institution. The crisis of the police apparatus is an international issue and the authors point to the case of the French police. Reverting to the thoughts of important authors in the sociological area, the authors resume the debate on some issues that they consider urgent: reformulation of the breadth of the concepts of risk and security to understand the police mission; enhancement of the police inside and outside corporations; review of the weight of the hierarchical rigidity or inflexibility on careers in a plural and flexible society.

Key words Occupational health, Health of the police officer, Security, Epidemiological risk, Social risk
Resumo Este artigo introduz uma discussão sobre a história e o uso dos conceitos de risco e segurança, aplicados ao sentido da missão policial. $O$ texto que se desenvolve de forma ensaística, mostra como ambos os termos se desenvolveram no âmbito da constituição das sociedades modernas $e$ industriais. Os autores partem da hipótese de que a estrutura organizacional da polícia em várias partes do mundo continua com a mesma lógica com que foi criada ao longo dos séculos XVIII e XIX e que esse formato está em crise: seja porque o conceito de risco e sua gestão atual se tornaram muito mais abrangentes; seja porque o conceito de segurança também se aprofundou e ampliou, fugindo ao âmbito da instituição policial. A crise dos aparatos policiais é uma questão internacional e os autores a exemplificam com o caso da França. Retomando o pensamento de autores importantes na área sociológica, os autores colocam em pauta o debate sobre algumas questões que consideram urgentes: reformulação da amplitude dos conceitos de risco e de segurança para compreensão da missão policial; valorização do policial dentro e fora das corporações; revisão sobre o peso da rigidez hierárquica ou da inflexibilidade na sua carreira, numa sociedade plural e flexivel. Palavras-chave Saúde do trabalhador, Saúde do policial, Segurança, Risco epidemiológico, Risco social 


\section{Introdução}

Muito se fala em nosso país sobre a crise da segurança pública e, em consequência, das corporações policiais e de seus aparatos. Alguns autores como Bretas ${ }^{1}$ chegam a se referir à sua decadência. No entanto, esse não é um problema apenas do Brasil ${ }^{2}$, como o mostra Lévy ${ }^{3}$ a respeito dessas corporações na França e no mundo. O argumento desses autores é que, em geral, a polícia continua com o mesmo formato estrutural e organizacional dos séculos XVIII e XIX quando paulatinamente foram sendo criadas na Europa, frente a um mundo pós-industrial radicalmente diferente na configuração de suas sociedades e nas suas necessidades de segurança ${ }^{4}$.

Tomemos aqui apenas o caso da França em que fica patente - e a mídia repercute - a insuficiência da força policial para assegurar a paz e tranquilidade social no cenário atual. Vejamos o caso documentado por Bonelli $i^{5}$ sobre a atuação policial frente a uma revolta dos jovens dos subúrbios de Paris, fato noticiado para o mundo inteiro. A situação que desencadeou a série de violências e chocou o país no fim de outubro de 2005 se iniciou com a morte trágica de dois adolescentes e os graves ferimentos de um terceiro, quando procuravam escapar a um controle policial em Clichy-sous-Bois. Esse evento acabou elevando o nível de revolta dos moradores de vários bairros pobres de Paris - num dos quais residiam os jovens que foram mortos - que acabaram por enfrentar as forças da ordem, incendiaram carros, depredaram equipamentos urbanos e realizaram diversos outros tipos de destruição.

Bonelli ${ }^{5}$ mostra que nos bairros que ocuparam o noticiário, os dados do Instituto Nacional de Estatística e de Estudos Econômicos (INSEE) indicavam, para os jovens de 15 a 24 anos, taxas de desemprego consideráveis e sempre superiores às do município em que moravam. Estratégias policiais e também sociais adotadas para controlar os moradores evidenciaram que não faltavam razões sociais para as explosões nas periferias. Não vem ao caso detalhá-las.

Apesar de um contexto sociocultural convulsionado e marcado pela revolta social, coube aos policiais "solucionar" a questão da "segurança". Fortemente armados com materiais ofensivos e defensivos, como flash-ball e teasers (armas nãoletais de descarga elétrica), eles confrontaram os jovens e preferiram atacar a investigar. Ficou notório que a polícia francesa continuava a dar prioridade à intervenção pela força ao invés da busca negociada dos conflitos e à prática de in- vestigação. Muitos dados começaram a ser divulgados mostrando isso. Por exemplo, o número de ocorrências registradas pelos serviços de polícia e dos gendarmes dobrou entre 1974 e 2004. Mas o número de pessoas interrogadas por infração às leis sobre drogas (ILS) multiplicouse 39 vezes; e os interrogatórios por suposta infração à lei sobre estrangeiros (ILE) foram maiores 8,5 vezes. Ao mesmo tempo, as taxas de elucidação dos casos diminuíram muito, passando de $43,3 \%$ a $31,8 \%$. Ou seja, a atividade policial concentrou-se em atuar frente a pequenos delitos, cuja constatação resulta da presença policial nas ruas, assim como da intensificação do controle de certos grupos sociais.

O caso francês nos lembra que, muitas vezes, a ordem e a desordem são coproduções, nas quais as instituições de segurança têm papel tão importante como as populações com as quais são confrontadas. No entanto, em casos como o referido, os endurecimentos policial e judicial, cujo efeito funesto para a coesão social e a ordem pública é conhecido, sempre acabam sendo reforçados.

Citamos esse caso para mostrar que os problemas das polícias vêm ocorrendo em vários países do mundo, inclusive no Brasil. No entanto, em nossa sociedade, os problemas parecem ser mais sérios, pois persistem destacadas singularidades da organização policial como elevada letalidade nos confrontos com delinquentes, quase ausência de transparência nas ações e frágil controle externo sobre suas atividades e as operações de seus agentes.

As razões são múltiplas e tentamos resumilas a seguir: (a) deterioração da vida social pelo aumento do número de pessoas excluídas nas periferias das grandes metrópoles, sobretudo dos jovens que continuam sendo as maiores vítimas do desemprego no mundo inteiro, ao mesmo tempo em que mantêm um lugar privilegiado nas estatísticas criminais. Na França atual, por exemplo, a taxa de desemprego é de $10,1 \%$ e entre os jovens de 18 a 25 anos é de $24,4 \%$. Num caso extremo, na Espanha, a taxa geral é de $20 \%$ e na juventude chega a 41,6\%. No Brasil, a despeito da estabilização econômica recente e da relativa melhoria das condições de vida dos mais pobres, para habitantes dos bairros que compõem a chamada periferia das regiões metropolitanas, os déficits sociais ainda são enormes e pesam duramente sobre crianças, adolescentes e jovens adultos; (b) aumento e sofisticação do crime organizado no mundo, utilizando-se, silenciosa e sorrateiramente para a realização de suas ações, de apa- 
ratos sofisticados, propiciados pelas tecnologias de informação e comunicação, à margem das tarefas e práticas usuais das polícias encarregadas da ordem pública; (c) aliciamento dos jovens que vivem em bairros pobres, desempregados, sem perspectivas e com pouca formação por parte do crime organizado, usados como "bucha de canhão" para alimentar e movimentar o mercado varejista de drogas e armas e de outros produtos ilegais; (d) aumento do número de armas sofisticadas e de maior letalidade em mãos de bandos urbanos e da população civil, enquanto as armas das polícias são de pouca resolutividade e as corporações continuam a contar com parcos recursos e são treinadas para repetir o que sempre rezaram as regras da segurança pública tradicional; (e) insuficiente investimento do Estado nas Corporações Policiais e em tecnologias de inteligência.

Não menos importantes, acrescentamos três outras mudanças fundamentais que ocorreram no país e no mundo e que devem ser consideradas quando tratamos do tema segurança pública: (a) aumento considerável da consciência de cidadania, o que significa maior valorização da vida e dos bens; (b) ampliação considerável do conceito de "segurança" - inclui-se a segurança pública - que saiu dos quartéis e das casernas para o mundo empresarial em todos os seus setores e segmentos (primários, secundários e terciários), assim como para referência de questões ambientais, de trabalho, de âmbito social e também individual; (c) atribuição de um papel muito mais complexo da polícia que tem que lidar ao mesmo tempo com o confronto direto e com dispositivos de proteção de grupos vulneráveis: novas e antigas modalidades de crime, (tráfico de armas e de mercadorias, delitos de ordem financeira e de Internet) e demandas novas como crimes contra crianças, adolescentes, mulheres, idosos e homossexuais. O policial de hoje deve ter consciência de tudo isso simultaneamente. E, portanto, necessita de excelente formação escolar e treinamento muito mais complexo e sofisticado.

Esse conjunto de mudanças sugere que as corporações policiais, nas sociedades contemporâneas, estão sujeitas a novos desafios, muito distintos e mais complexos face aos enfrentados no passado, desde a criação moderna dessas agências de controle social. Certamente, um dos maiores desafios é realizar suas tarefas institucionais com eficiência e respeito aos direitos fundamentais dos cidadãos. Não menos importante é preservar a integridade deste corpus de agentes do estado diante das novas situações de risco em que eles se veem e se encontram sujeitos.
Este texto pretende ser uma contribuição para este debate. Centrado em uma discussão sobre os conceitos de risco e segurança sugere o quão complexas são essas relações nas sociedades contemporâneas. Ao fazê-lo, aborda suas implicações práticas na vida cotidiana dos policiais, o que permite identificar e indicar alguns pré-requisitos para garantir-lhes segurança e proteção. Tomamos como inspiração o exemplo da crise policial na França - o país que foi berço das Corporações Policiais do Ocidente ${ }^{6}$ - sobretudo porque ele projeta a dimensão mais universal das questões propostas e auxilia a não introjetar os problemas vividos na sociedade brasileira apenas como questões locais.

\section{Risco como profissão e ampliação do conceito}

O termo histórico que liga a polícia ao contexto das sociedades modernas é o conceito de risco, vivenciado por ela como profissão e práti$\mathrm{Ca}^{7,8}$ e de forma superlativa nas contingências da sociedade contemporânea.

A noção de risco é uma das criaturas nascidas na modernidade industrial, mais precisamente no século XVII, servindo ora como elemento de precaução no nível pessoal ora como elemento de cálculo frente às probabilidades de que algo ruim e indesejável possa acontecer. Riscos, diz Beck", "são formas sistemáticas de lidar com os perigos e as inseguranças induzidas e introduzidas pelo próprio processo de modernização”. Ou ainda, riscos constituem a regra geral dos jogos e das aventuras humanas. Não é por acaso que esta noção tenha surgido na florescência do capitalismo industrial, uma vez que ela só poderia emergir numa sociedade que mirasse o futuro como um espaço a conquistar.

Hayes ${ }^{10}$ refere que o conceito de risco é um campo acadêmico que não tem fronteiras definidas, frequentemente apresentando lacunas de coerência conceitual. Duas tendências concomitantes, no entanto, podem ser notadas historicamente. De um lado, risco como algo negativo e o correr risco como escolha individual frente a algo que pode dar certo ou errado. De outro, a ideia de risco como algo inerente à vida ${ }^{11}$, aos desafios do progresso universal e ao desenvolvimento pessoal e do mundo.

No primeiro caso, o termo está ligado à prevenção de eventos negativos. Podemos exemplificá-lo com o seu uso no campo da saúde, sendo ele central para a epidemiologia e vinculado à ideia de desvio e perigo a ser afastado. Do ponto 
de vista operacional, a epidemiologia trabalha com a teoria das probabilidades, visando à redução de incertezas na tomada de decisões dos agentes de saúde. Mesmo quando atua de forma qualitativa buscando compreender redes de relações e vivências que favoreceriam determinados comportamentos que levam à contaminação ou a contágios perigosos para o adoecimento, o profissional de saúde inclui a ideia de risco dentro de sua conotação de perigo e evitação.

Do ponto de vista dos Policiais, seu "risco epidemiológico" se materializa, principalmente, nos confrontos armados, nos quais se expõem e podem perder a vida. É certo que o risco é inerente à natureza das operações policiais. Não é menos certo, porém, que orientações institucionais, emitidas pelas autoridades hierarquicamente superiores e não raro lastreadas em políticas governamentais de segurança pública podem agravar esse quadro se risco. Políticas do tipo "mão dura", voltadas para o enfrentamento a qualquer custo do crime urbano não raro potencializam o risco. No mesmo sentido, o desempenho do chamado "bico", em geral exercício de atividades de segurança para o mercado privado nas horas de folga ou descanso da ocupação profissional oficial, exerce efeitos similares.

A probabilidade que têm de sofrer graves lesões, traumas e mortes encontra respaldo nas altas taxas de óbito por violência de que são vítimas, dentro e fora de seu ambiente de trabalho e nos efeitos pós-traumáticos dos que continuam vivos. Essas taxas de óbito são cerca de 10 vezes mais elevadas no Rio de Janeiro, por exemplo, do que as da população em geral, como mostram estudos de Muniz ${ }^{12}$ e Souza e Minayo ${ }^{7}$. E os efeitos pós-traumáticos foram medidos por Maia et al. ${ }^{13}$ num estudo local sobre um grupo de policiais de elite brasileiro, em que a prevalência para (pós-traumatic stress disorder) "full PTSD" e "partial PTSD" foram de 8.9\% e 16\%, respectivamente. Comparado com outro grupo que não sofreu sequelas pós-traumáticas, os autores encontraram entre os policiais, cinco vezes mais divorciados (21.6\% vs. $4.3 \%$ ), elevada proporção de pessoas com sérios agravos à saúde (64.3\% vs. $6 \%$ ), que haviam consultado várias vezes o médico no espaço de 12 meses e tinham ideação suicida ( $35.7 \%$ vs. $5.2 \%$ ). Gershon et al. ${ }^{14}$ ressaltam que os problemas vivenciados pelos policiais tendem a se acumular com os anos e a se expressar em sua vida conjugal, familiar e social - se não recebem cuidados devidos à saúde. Os efeitos mais comuns são: alcoolismo e jogos de azar; vivência de ansiedade; depressão; sinto- mas de burnout, comportamento agressivo; maior propensão a sofrer estresse negativo, a cometer violência doméstica e a ter problemas de comportamento no trabalho. Com pequenas diferenças entre os termos utilizados, também foram encontrados esses efeitos sobre a saúde de policiais civis ${ }^{15}$ e militares do Rio de Janeiro ${ }^{16}$, de Minas Gerais ${ }^{17}$ e de Pernambuco ${ }^{18}$.

Etimologicamente, porém, a palavra risco deriva do vocábulo latino "riscare", e tem sentido positivo, associado à ideia de ousar. Do ponto de vista sociológico, risco significa uma opção institucional e não um destino pessoal ${ }^{19}$. No caso, as corporações policiais poderiam ser configuradas como organizações nas quais o risco como escolha individual é previsível e inclusive desempenha um papel inerente às condições de trabalho, ambientais e relacionais. Os profissionais que as compõem têm consciência disso. Seus corpos estão permanentemente expostos e seu espírito não descansa num sentido de alerta que as investigações demonstram ${ }^{8}$. Em todas as pesquisas realizadas com policiais observamos que eles, ao mesmo tempo temem as dificuldades e sentem os perigos, relatam "o vício da adrenalina" que os mantém prontos para a ação. Em estudos com os policiais civis e militares do Rio de Janeiro ${ }^{15,16,20} 75 \%$ deles disseram que se pudessem escolheriam a mesma profissão, e no caso dos policiais de Minas Gerais essa proporção chega a $80 \%{ }^{17}$, embora esse elevado percentual de adesão em ambos os Estados escondem uma proporção entre 25 e $30 \%$ dos ressalvariam sua escolha pela condição de receberem melhores salários.

Embora sem ligação direta com a instituição policial, é no mesmo seio cultural e de mentalidades - se considerarmos a ideia histórica de "longa duração" (termo cunhado por Fernand Brau$\mathrm{de}^{21}$ ) - que ambas, a noção de risco e a noção de polícia, nasceram, sob a orientação ideológica de que o Estado deveria ter o domínio sobre as pessoas e as coisas e ter previsibilidade das práticas sociais. Em "Vigiar e Punir" Foucault ${ }^{22}$ analisou as duas modalidades de poder que foram paulatinamente conformando os indivíduos e a sociedade da era industrial: a disciplina dos corpos e sua inclusão ou reclusão nas instituições sociais; e as biopolíticas do poder exercido sobre o conjunto e sobre cada um dos indivíduos.

Desta forma, o sentido de risco, adequado para descrever a situação intrínseca à profissão de policial, combina a visão epidemiológica e a visão sociológica. A primeira lhe dá parâmetros quanto à magnitude dos perigos, dos tempos e 
dos locais de maior ocorrência das fatalidades. A segunda compreende a convergência entre duas dimensões de sua ação: uma objetiva, representada tanto pelas características de estrutura e funcionamento das agências policiais, que incluem condições de trabalho, regras de orientação da conduta profissional e definição de metas de ação. Tais características limitam as opções dos policiais no desempenho de suas atividades. E uma dimensão subjetiva em que o risco sob a ótica dos policiais tem o sentido de ousadia, bravura e de escolha individual diante de situações de enfrentamento. É justamente nos casos em que tais dimensões se interpenetram que o risco pode ser potencializado ou minimizado. Um bom exemplo são as recomendações de treinamento do Comitê Internacional da Cruz Vermelha, em casos de confrontos armados. Quanto mais o policial faz apelo ao emprego de força física, maior a exposição ao risco. Contra essa tendência, são estimulados os treinamentos que apontam na direção do aprendizado de técnicas de negociação e menor recurso ao uso sistemático da força física visando, assim, conferir maior proteção aos policiais.

A noção de riscos se agigantou como ideia obrigatória nessa etapa histórica do capitalismo pós-industrial, ultrapassando seu sentido tradicional e entrando como tema na administração do cotidiano e na gestão de grandes e pequenos negócios. Alguns autores como Beck ${ }^{9}$ e Giddens ${ }^{23}$ têm adotado o termo "sociedade do risco" para falar do momento presente em que cada vez mais a aculturação da natureza criou artefatos tecnológicos. Beck ${ }^{9}$ fala sobre riscos que contribuem decisivamente para criar e gerar consequências de alta gravidade para a saúde humana e para o meio ambiente, desconhecidas no longo prazo e que, quando descobertas, tendem a ser irreversíveis. Entre esses, são especialmente mencionados os ecológicos, os químicos, os nucleares, os genéticos e os econômicos, produzidos industrialmente, externalizados economicamente, individualizados juridicamente, legitimados cientificamente e minimizados politicamente.

Os avanços sociais, científicos e tecnológicos, na teoria e na prática, vêm mostrando que todas as sociedades têm de se confrontar com o aleatório e com a erupção da incerteza e do inesperado. E essa vivência se torna tão mais aguda, quanto mais complexos são os dispositivos tecnológicos envolvidos no atendimento das necessidades humanas básicas ou socialmente construídas. Frente a sistemas tão complexos criados, paradoxalmente, para o cuidado e o conforto humano, são quase infinitas as possibilidades de um determinado fator combinar com outro e mais outro e mais outro e provocar um determinado resultado ${ }^{10}$.

Para complicar mais ainda o sentido das mudanças, convém considerar que as lições do passado têm efeito explicativo relativo para entender os desafios do presente, sobretudo, por causa do avanço tecnológico que torna obsoleto a maior parte de tudo o que utilizamos há 20 anos. Assim, frequentemente o que aconteceu antes não pode mais ser tomado como único parâmetro de referência para prever ou prevenir o que possa vir a ocorrer. O que não muda, e sim se enriquece, é a capacidade dos atores sociais, diante da magnitude dos problemas sociais que enfrentam em refletir criticamente a respeito das peculiaridades contemporâneas e agir para transformar constantemente o mundo a sua volta.

\section{Segurança como missão e ampliação do conceito}

A ideia de Segurança Pública com a qual as forças policiais trabalham está definida na Constituição de 1988: ela constitui a garantia que o Estado oferece aos cidadãos, por meio de organizações próprias, contra todo o perigo que possa afetar a ordem pública, em prejuízo da vida, da liberdade ou dos direitos de propriedade. A promoção da Segurança Pública é a essência da missão dos policiais e deriva do campo jurídico.

A ideia de segurança - assim como a instituição da polícia e do conceito de risco - nasceu nos séculos XVII e XVIII quando os Estados Absolutistas passaram a planejar o desenvolvimento e a organização das cidades visando a vigilância dos citadinos e a oferta de condições de convivência civilizada ${ }^{6}$. Também essa noção tem avançado no tempo e em várias direções.

O mais abrangente dos termos atuais relativos ao tema é o de segurança global da população que se fundamenta no direito natural à vida, à saúde, à propriedade e à incolumidade das pessoas e do patrimônio. Esse conceito tem origem na ideia de segurança coletiva, desenvolvida pela Liga das Nações e pela ONU, principalmente na configuração no seu Conselho de Segurança ${ }^{24}$. Mas esse termo se desdobrou e assumiu novas características pela aceleração do conhecimento científico e tecnológico no âmbito da produção e do trabalho, da vida doméstica e da vida cotidiana. O contraponto do conceito de risco é a noção de segurança e o desejo de segurança absoluta que se opõem ao medo difuso e inespecífico do 
individuo frente aos danos que o outro possa causar a ele e a seus bens e aos excessos tecnológicos que o rondam e que não domina.

É importante assinalar também que como cidadãos e trabalhadores os policiais têm direito a Segurança Pessoal. Neste segundo caso, entramos no âmbito do direito. O conceito representa a sistematização de normas destinadas a prevenir acidentes, eliminar condições inseguras do trabalho, e a oferecer acesso aos serviços que o protejam e o assistam. Ou seja, cuidando da segurança pública os policiais são, também, servidores públicos protegidos pela Constituição que lhes assegura o direito à integridade física, moral e mental no exercício profissional.

Existe hoje uma hipótese ou ponto de partida que considera haver uma crise no modelo liberal de organização policial, cujo principal sintoma é o aumento da insegurança. A ideia de segurança que correspondia a uma necessidade histórica da modernidade tornou-se muito restrita. No caso da segurança pública, o modelo do passado que ainda persiste não corresponde ao mundo pluralista contemporâneo. Na maioria das vezes, as formas de controle e proteção fazem parte dos próprios processos de produção de bens e servi$\operatorname{ços}^{3,25,26}$. Desta forma, a questão da segurança apresenta problemas em níveis impensáveis, por exemplo, no âmbito da comunicação virtual global, do mundo financeiro, de negócio, do crime organizado, assim como no âmbito da vida privada, como lembra Castel ${ }^{4}$. Do ponto de vista privado, nunca houve tantos aparatos para garantir a vida e a incolumidade dos cidadãos e nunca as pessoas se sentiram tão frágeis e tão desamparadas ${ }^{27}$.

No mundo do trabalho, os estudos sobre segurança mostram, por exemplo, que todas as combinações de fatores que levariam a prever um acidente numa determinada fábrica atualmente, só em $20 \%$ a $25 \%$ dos casos poderiam ser previstos a partir dos que antes ocorreram. Ou seja, mesmo se tivéssemos elementos que nos permitissem pensar na ocorrência de uma catástrofe, a parte em que a experiência do acontecido auxiliaria no novo cálculo de probabilidade seria limitada.

Ao mesmo tempo, a existência de mais segurança tanto no âmbito privado como público ocorre com a concomitante sensação de mais insegurança e, do ponto de vista filosófico, o conceito de segurança se vincula às expectativas do cidadão moderno e faz um contraponto com a noção de risco: evidencia o avanço atingido pela humanidade em seu estágio atual quanto à cons- ciência de cidadania, ressalta o interesse dos indivíduos na defesa de seu bem-estar. No entanto, nomear a "insegurança" como um termo característico da contemporaneidade é falar mais de "sentimento de insegurança" do que do fato em si. Em seus estudos Gidden $s^{23}$ pondera que não é verdade que vivemos mais perigosamente agora do que há 100 ou 200 anos. Apesar de todas as situações perigosas, da pobreza e da miséria persistentes, apesar de todos os novos riscos criados pelas tecnologias, dificilmente alguma época histórica e algum contexto social foram tão seguros, na visão do autor.

Desta forma, os termos risco e insegurança continuam bastante fluidos e subjetivos. E as representações de urgência sobre eles sempre estarão ligadas à agudeza da consciência de cidadania e às exigências sociais de valorização da vida $^{28,29}$. Como assinala Giddens ${ }^{23}$, de um lado, sem a ciência e a tecnologia - que hoje estão presentes em quase tudo o que usamos ou consumimos - sequer teríamos consciência de muitos dos perigos que ameaçam as sociedades e os indivíduos. De outro, é real o fato de que exista uma série de fatores aleatórios incomensuráveis a rondar nossa existência contemporânea, tal o grau de complexidade da aculturação da natureza que nossa sociedade atual alcançou.

Concluindo, é preciso ressaltar que a visão ampliada e contemporânea dos conceitos de risco e de segurança nada tem a ver com o sentido unicausal dos termos que alimentou o raciocínio positivista da maioria das instituições modernas, inclusive as da saúde e a polícia. Compreender e aceitar essa complexa realidade demanda, com urgência, o uso e a experimentação de novos instrumentos teóricos para análise, julgamento e novas formas de organização das práticas.

\section{Considerações finais}

Em primeiro lugar, é preciso valorizar o policial, dentro e fora das Corporações

Ao mencionar os estudos históricos que descrevem a relação entre a polícia e o Estado, Muniz $^{30}$ ressalta que são raros os trabalhos que valorizam os aspectos cotidianos das atividades de polícia. Perguntamo-nos se isso não tem a ver com a mentalidade da nossa sociedade para quem o ser humano policial nada mais é do que um objeto instrumental de produção de segurança pública.

É preciso ressaltar, no entanto, que o policial de hoje, em geral, entra na tropa mais instruído, 
com ensino médio concluído e muitos possuem curso superior completo ou em andamento, diferentemente do que ocorria no passado ${ }^{16,17,20}$. A maioria deles se orienta preferencialmente para o campo do direito, à falta de uma formação superior especializada mais adequada à natureza dos serviços que prestam. Além das transformações conceituais já citadas que trazem uma nova visão sobre segurança e que, com certeza fazem parte do repertório vital desse servidor - mesmo que não seja de forma sistematizada - ele agora está mais sensível às demandas da sociedade em geral por segurança pública e organiza entidades associativas, muitas delas inspirando-se em técnicas de movimentos sociais, na defesa de seus direitos. Certamente tais mudanças ocorrem ao interior do processo democratização do país que vem expandindo o sentido da cidadania. Nessa medida, os próprios policiais se vêem também como cidadãos comuns, consumidores e partícipes dos movimentos comunitários e sociais.

No entanto, as Corporações continuam muito fechadas, embora sejam pressionadas a se abrir pela sociedade civil organizada e pela política de direitos humanos. As tensões aparecem, sobretudo, no emprego da força coercitiva. Teoricamente os policiais sabem que, embora constitucionalmente eles tenham o monopólio do uso da violência em nome do Estado, seu trabalho não deve mais ser um serviço truculento: devem valer-se da força quando necessário, mas, sobretudo, recorrer a técnicas de inteligência policial sempre que possível. No entanto, para muitos é ainda motivo de estresse o fato de exercerem tarefas que lhes parecem contraditórias: por um lado, observar e estar atentos aos direitos dos cidadãos ainda que delinquentes ${ }^{17}$; por outro, terem que responder às demandas por maior eficiência, o que, para o senso comum, pode ser interpretado como caução para o uso abusivo da força.

Presentemente, as políticas de segurança pública não podem deixar de focalizar as singularidades desse trabalho profissional e, em especial, deixar de considerar policiais como atores relevantes, capazes de estimular mudanças organizacionais nas Corporações. Segundo qualquer teoria administrativa contemporânea, participação é a palavra chave para o enriquecimento institucional: todo ator social que colabora para melhorar sua organização enriquece-a e a torna mais dinâmica e complexa. Nossa tese é de que, sem levar em conta a subjetividade desses agentes, a segurança pública tão almejada poderá se resumir a uma política burocraticamente exercida, o que é ruim para eles e para a população a quem servem. É na confluência entre subjetividade e participação, que esses atores poderão efetivamente contribuir para estimular mudanças institucionais nas corporações de forma a romper com o excessivo corporativismo e reequacionar suas missões profissionais de forma a conciliar aplicação de lei e ordem no contexto do respeito aos direitos humanos.

No entanto, é preciso dar relevância também a outro fato. Mesmo que a coesão interna, reforçada pelo corporativismo, seja característica dessas organizações, existem focos de insatisfação dentro das corporações policiais. Essa insatisfação vem dos que aí estão apenas para ter um emprego, porque se acomodaram, ou ainda por parte dos que estão totalmente engajados, mas que se ressentem das condições adversas de trabalho. Os principais motivos de insatisfação que a bibliografia mostra, geralmente decorrem (a) da frustração e mesmo do ressentimento pela falta de reconhecimento dos superiores e da população; (b) das queixas sobre salários, condições de trabalho, qualidade de vida e inadequação organizacional e dos equipamentos de uso pessoal; (c) descontentamento com a justiça que consideram leniente; (d) o fato de se sentirem quase permanentemente ameaçados ${ }^{15-17,31}$.

Assim, embora possamos concluir que existem resistências e descontentamento em qualquer categoria de trabalhador, as autoridades deveriam levar em conta o que ocorre com os policiais, uma vez que sua valorização e satisfação são prérequisitos de nossa segurança e proteção.

É preciso reformular a amplitude dos conceitos de risco e de segurança. Ressaltamos a importância das corporações elaborarem uma discussão mais aprofundada sobre os termos sobre os quais se assenta, historicamente, a institucionalização da Polícia. Poderia parecer demasiadamente acadêmica esta proposta quando o dia a dia das corporações é quase uma atividade reativa ao excesso de acirramento com que têm que lidar. No entanto, entendemos que nenhum gestor hoje pode desprezar a compreensão dos fundamentos históricos que estruturaram essa instituição, se quiser fazer propostas novas. É inegável reconhecer a existência de uma crise que atravessa todas as organizações policiais do mundo. Seu formato institucional foi concebido numa época de plena efervescência da sociedade industrial e de nascimento e crescimento das cidades, organizadas sob o ritmo das fábricas. Mudaramse as fábricas, mudaram-se as cidades, o mundo virtual chegou para ficar e as noções de tempo e espaço se transformaram. Não sem motivos, es- 
tão hoje em discussão tanto a filosofia quanto o sentido e a prática policial no âmbito da administração pública.

É preciso repensar o peso da rigidez hierárquica numa sociedade plural e flexível. Como um corolário das menções anteriores, outro ponto surgido insistentemente nas pesquisas que fizemos sobre policiais, sobretudo a Militar, é a questão da hierarquia e da disciplina das casernas como essência organizacional. Observamos que esse tipo de organização das relações de trabalho não é bom nem para os subalternos e nem para os oficiais. Nas entrevistas feitas com a Polícia Militar do Rio de Janeiro ${ }^{16,17}$, observamos uma contradição no discurso. De um lado, esses agentes comentam que seria impossível a vida sem a tradição hierárquica e, de outro, ressaltam as dificuldades que enfrentam com essa forma de gestão: esse discurso não é apenas de cabos e soldados, mas também de vários comandantes quando se referem ao ônus da decisão solitária sobre ações de elevado risco para seu grupo e para a sociedade.

Desde os clássicos do pensamento sociológico, como Durkheim e Weber, conhecem-se os efeitos da disciplina social, da qual a disciplina militar é parte. Por um lado, controles institucionais fundados na disciplina militar podem coibir ou restringir práticas de corrupção, favoritismo pessoal, ingerência política e estabelecer parâmetros para normalização de comportamentos e práticas. Tais efeitos, porém são de curto alcance quando se referem à qualidade do trabalho que a polícia ostensiva desenvolve nas ruas. O rigor que enfatiza a obediência à hierarquia e sua conformidade com as regras corporativas contrastam fortemente com a precariedade dos instrumentos de controle e avaliação das atitudes e práticas policiais ${ }^{30}$. No caso dos policiais civis, a organização do trabalho não é tão rígida, mas ocorre um achatamento funcional na atribuição de atividades, e eles não têm um plano de carreira efetivo que estimule o reconhecimento das potencialidades individuais ${ }^{15}$.

Em estudo de grande importância sobre a Polícia Militar, Muniz et al. ${ }^{12}$ listaram uma gama de aspectos negligenciados que precisam ser levados em consideração em projetos de mudan- ça. Reconhecendo com outros autores que essa corporação "desfruta da imagem de ser a mais organizada das instituições policiais”, esses autores mencionam uma série de problemas práticos que escapam à rigidez hierárquica: precariedade logística; fraca articulação entre as companhias no interior dos batalhões; ineficiência dos serviços internos responsáveis por essa articulação; ausência de planejamento; precária estrutura de levantamento, distribuição e processamento de informações; escalas de trabalho dessincronizadas; rigidez do regimento interno em vigor (herança obsoleta da ditadura militar); centralização e padronização ao extremo; infindáveis complicações hierárquico-burocráticas enfrentadas a cada passo; pouquíssimo investimento na qualificação e reciclagem dos policiais de ponta; indigência dos critérios de avaliação de desempenho ${ }^{12}$.

Concluímos fazendo jus às mudanças organizacionais hoje existentes no mundo do trabalho. Ao contrário da rigidez militar (no caso da polícia militar) ou do achatamento da carreira (no caso da polícia civil), a organização contemporânea do trabalho exigiria dos policiais não apenas seu esforço físico como sua energia mental; privilegiaria o trabalho em grupo; diminuiria os níveis hierárquicos e valorizaria as potencialidades, a contribuição e a produtividade do grupo e de cada um; conceberia a qualidade não como um controle externo, mas como parte da atividade de cada policial; valorizaria e responsabilizaria o policial de qualquer instância; premiaria e destacaria o desempenho de cada um e do seu grupo; aproveitaria seu saber, instituindo estratégias de mudanças internas a partir da experiência individual e coletiva.

$\mathrm{Na}$ verdade, não temos jurisdição e poder para dizer se a proposta de flexibilização seria a melhor solução organizacional para as corporações policiais. No entanto, juntando nossa palavra com a de Muniz ${ }^{30}$ e Mussumeci ${ }^{32}$ ressaltamos a necessidade de que a instituição policial enfrente uma séria discussão sobre sua reestruturação, para atender às exigências de uma sociedade que deseja uma polícia bem informada, bem treinada, flexível e ágil. 


\section{Colaboradores}

MCS Minayo e S Adorno participaram igualmente de todas as etapas de elaboração do artigo.

\section{Referências}

1. Bretas ML. Observação sobre a falência dos mode los policiais. Tempo Social 1997; 9(1):79-94.

2. Santos JVT. A arma e a flor: formação da organização policial, consenso e violência. Tempo SocialRevista de Sociologia 1997; 9(1):155-167.

3. Lévy R. A crise do sistema policial francês hoje: da inserção local aos riscos europeus. Tempo SocialRevista de Sociologia 1997; 9(1):53-77.

4. Castel R. Les Métamorphoses de la question sociale. Paris: Gallimard; 1999.

5. Bonelli L. Nouveau millénaire, défis libertaires: révolte des balieues, raizons d'unne colère. [texto da Internet].2011 [acessado $2011 \mathrm{dez} 10$ ]. Disponível em: http://www.monde-diplomatique.fr/2005/12/ BONELLI/12993.

6. Holloway T. Polícia no Rio de Janeiro: repressão e resistência numa cidade do século XIX. Rio de Janeiro: Editora FGV; 1997.

7. Souza ER, Minayo MCS. Policial, risco como profissão: morbimortalidade vinculada ao trabalho. Cien Saude Colet 2005; 10(4):917-928.

8. Minayo MCS, Souza ER, Constantino P. Riscos percebidos e vitimização de policiais civis e militares na (in)segurança pública. Cad Saude Puública 2007; 23(1):2767-2781.

9. Beck U. Risk Society: Towards a New Modernity. Londres: Editorial Sage; 1992.

10. Hayes M. On the epistemology of risk: Language, logic and social science. Social Science and Medicine 1992; 35(4):401-407.

11. Heideger M. Ser e tempo. São Paulo: Editora Abril; 1980. (Coleção Pensadores)

12. Muniz J, organizadora. Mapeamento da vitimização de policiais no Rio de Janeiro [Relatório de Pesquisa]. Rio de Janeiro: Iser, Unesco, MJ; 1998.

13. Maia DB, Marmar CR, Metzler T, Nóbrega A, Berger W, Mendlowicz MV, Coutinho ES, Figueira I. Post-traumatic stress symptoms in an elite unit of Brazilian police officers: Prevalence and impact on psychosocial functioning and on physical and mental health. J Affect Disord 2007; 97(1-3):241-245.

14. Gershon RR, Lin S, Li X. Work Stress in Aging Police Officers. J Occup Environ Med 2002; 44(2):60167.

15. Minayo MCS, Souza ER. Missão Investigar: entre o ideal e a realidade de ser policial. Rio de Janeiro: Editora Garamond; 2003.

16. Minayo MCS, Souza ER, organizadoras. Missão Prevenir e Proteger: estudos sobre condições de vida, saúde e trabalho dos policiais militares. Rio de Janeiro: Editora Fiocruz; 2008.
17. Minayo MCS, coordenadora. Avaliação dos Riscos Ambientais e das Condições de Saúde dos Policiais Militares de Minas Gerais. [Relatório de pesquisa]. Belo Horizonte: Fundação Guimarães Rosa/Secretaria de Defesa Social; 2011.

18. Ferreira DKS, Bonfim C, Augusto LGS. Fatores associados ao estilo de vida de policiais militares. Cien Saude Colet 2011; 16(8):3403-3412.

19. Bernstein PL. Desafio dos Deuses: a fascinante história do risco. Rio de Janeiro: Campus; 1997.

20. Minayo MCS, Souza ER, Constantino P, Assis SG, Carvalhaes OR. (In)segurança profissional e (in)segurança pública. Coleção Segurança com Cidadania 2009; 1:195-230.

21. Fernand B, Matthews S. On History. Chicago: The University of Chicago Press; 1982.

22. Foucault M. Vigiar e punir. Petrópolis: Editora Vozes; 1977.

23. Giddens A. Modernidade e Identidade. Rio de Janeiro: Jorge Zahar Editores; 2002.

24. Azambuja MC. Os mecanismos de segurança coletiva. Rev Estudos Avançados da USP 1995; 9(25):139147.

25. Ocqueteau F. A expansão da segurança privada na França. Provatização submissa da ação policial ou melhor gestão da segurança coletiva? Tempo SocialRevista de Sociologia 1997; 9(1):185-195.

26. Monjardet D. O que faz a polícia. São Paulo: EDUSP, NEV-USP; 2003. (Coleção Polícia e Sociedade, n. 10)

27. Hobsbawn EJ. Globalização, democracia e terrorismo. São Paulo: Companhia das Letras; 2007.

28. Chesnais JC. Histoire de la violence en Occident de 1800 à nos jours. Paris: Robert Laffont Éditor; 1981.

29. Burke P. Violência social e civilização. Braudel Papers $1995 ; 12: 1-8$.

30. Muniz J. Ser policial é sobretudo uma razão de ser: cultura e cotidiano da Polícia Militar do Rio de Janeiro [tese]. Rio de Janeiro: UCAM; 1999.

31. Kroes WH, Margolis BL, Hurrell JJ. Job stress in policemen. Journal of Police Science \& Administration $1974 ; 2(2): 145-155$.

32. Musumeci L. Relatório de Desenvolvimento $\mathrm{Hu}$ mano do Município do Rio de Janeiro. Musumeci L. In: Violência, criminalidade e segurança. Cap.5. Rio de Janeiro: PNUD, IPEA, Prefeitura Municipal; 2000. [acessado 2012 jun 12]. Disponível em: http:/ /saturno.no.com.br/notitia/leitura/pdf/5capitulo. pdf]. 